\title{
Germ Line, Stem Cells, and Epigenetic Reprogramming
}

\author{
M.A. Surani, G. Durcova-Hills, P. Hajkova, K. Hayashi, and W.W. Tee \\ Wellcome Trust Cancer Research UK Gurdon Institute, University of Cambridge, \\ Cambridge CB2 1QN, United Kingdom
}

\begin{abstract}
The germ cell lineage has the unique attribute of generating the totipotent state. Development of blastocysts from the totipotent zygote results in the establishment of pluripotent primitive ectoderm cells in the inner cell mass of blastocysts, which subsequently develop into epiblast cells in postimplantation embryos. The germ cell lineage in mice originates from these pluripotent epiblast cells of postimplantation embryos in response to specific signals. Pluripotent stem cells and unipotent germ cells share some fundamental properties despite significant phenotypic differences between them. Additionally, early primordial germ cells can be induced to undergo dedifferentiation into pluripotent embryonic germ cells. Investigations on the relationship between germ cells and pluripotent stem cells may further elucidate the nature of the pluripotent state. Furthermore, comprehensive epigenetic reprogramming of the genome in early germ cells, including extensive erasure of epigenetic modifications, is a critical step toward establishment of totipotency. The mechanisms involved may be relevant for gaining insight into events that lead to reprogramming of somatic cells into pluripotent stem cells.
\end{abstract}

The maternal inheritance of key pluripotency transcription factors and epigenetic modifiers in the mammalian oocyte are important components of the totipotent zygote; they contribute to the foundation of the pluripotent primitive ectoderm cells in the inner cell mass (ICM) of blastocysts (Surani et al. 2007). The latter are the precursors of all somatic tissues and germ cells in vivo, as well as the pluripotent embryonic stem (ES) cells in vitro. The germ cell lineage in mice originates from the pluripotent epiblast cells of the early postimplantation embryo commencing at embryonic day (E) 6.25 (Hayashi et al. 2007). In the mouse, there is no compelling evidence for the existence of preformed germ cell determinants in the zygote or early embryo, as is the case in some other model organisms (Strome and Lehmann 2007); instead, specification of primordial germ cells (PGCs) occurs from pluripotent cells according to the "stem cell model" in response to signals from the extraembryonic tissues (Lawson and Hage 1994; McLaren 2003; Surani et al. 2007).

In postimplantation embryos, development of pluripotent epiblast cells from the ICM is accompanied by a series of epigenetic changes, such as silencing of specific genes including stella, a marker of pluripotency and germ cells, as well as random $\mathrm{X}$ inactivation in cells of female embryos (McMahon et al. 1981). These pluripotent epiblast cells are the immediate precursors of primordial germ cells, as well as of the in-vitro-derived pluripotent epiblast stem cells (EpiSCs), which differ from pluripotent ES cells derived from the ICM (Brons et al. 2007; Tesar et al. 2007). The unipotent germ cells are the only cells during postimplantation development to reacquire some characteristics that are closer to those of the ICM following epigenetic reprogramming of early germ cells (Hayashi et al. 2007; Surani et al. 2007). This is reflected in the properties of the embryonic germ (EG) cells derived from early PGCs (Matsui et al. 1992; Resnick et al. 1992) that are more like ES cells, and not like EpiSCs despite their origin from postimplantation epiblast cells (Fig. 1).
The extensive epigenetic reprogramming of the genome in the germ cell lineage includes comprehensive erasure of epigenetic modifications (Hajkova et al. 2002, 2008). The underlying mechanisms, including reprogramming of somatic cells, are of wide interest. Analysis of the germ cell lineage may also provide a deeper understanding of the pluripotent state itself, as well as the relationship between germ cells and pluripotent stem cells. In this regard, our recent studies on the arginine methylase Prmt5 may provide insights into the link between pluripotent stem cells and the establishment of germ cells at the molecular level (W.W. Tee, unpubl.). Indeed, all pluripotent stem cells generated and maintained in vitro by definition are potential germ cells.

\section{THE STEM CELL MODEL FOR PGC SPECIFICATION IN MICE}

PGC specification in vivo follows after pluripotent epiblast cells gain competence in response to signals from the extraembryonic tissues, notably BMP4 and the Smad1/5 signaling pathways (Lawson et al. 1999; Tremblay et al. 2001; Hayashi et al. 2002). This triggers expression of Blimp1/Prdm1, the key determinant of PGC specification, which is initially detected in a few cells present within the proximal epiblast cells (Ohinata et al. 2005; Vincent et al. 2005). Expression of Blimp1/ Prdm1 initiates a cascade of events, including extensive epigenetic reprogramming of the germ cell lineage and reactivation of the inactive X chromosome (Surani et al. 2004; de Napoles et al. 2007; Sugimoto and Abe 2007; Chuva de Sousa Lopes et al. 2008). Reactivation of the inactive $\mathrm{X}$ is also seen earlier during the establishment of pluripotent cells in the ICM (Mak et al. 2004; Okamoto et al. 2004). As the germ cells migrate into the gonads, this lineage is maintained in the unipotent state probably by the Blimp1-Prmt5 complex (Ancelin et al. 2006). Notably, dedifferentiation of PGCs into EG cells is coupled with 


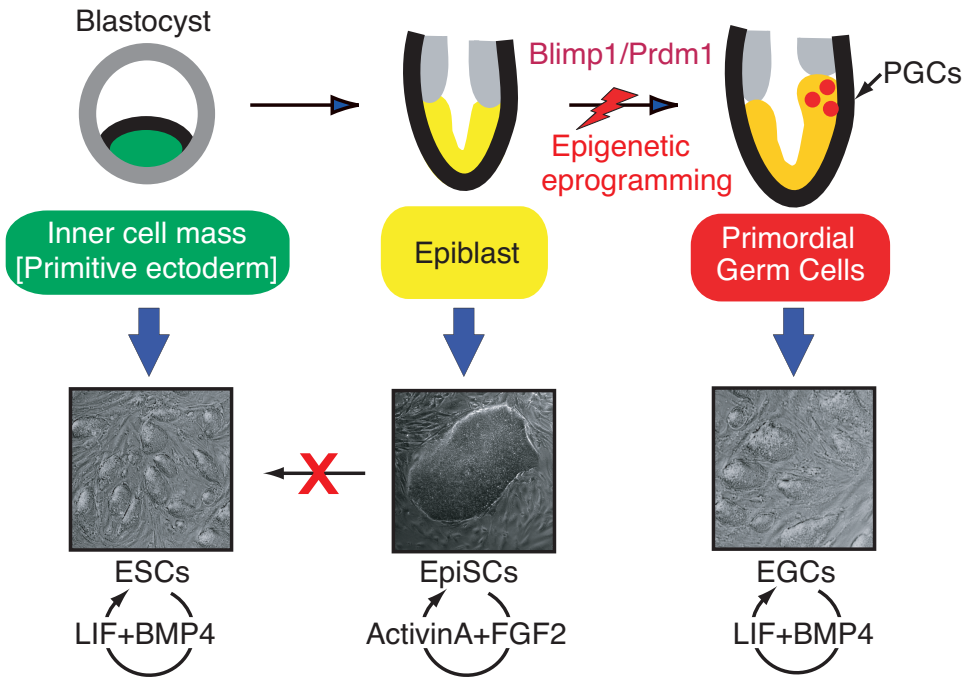

PLURIPOTENTSTEM CELLS

\begin{abstract}
Figure 1. Establishment of pluripotent cells and the emergence of the germ cell lineage. The primitive ectoderm cells develop into pluripotent epiblast cells of postimplantation embryos. Specification of primordial germ cells (PGCs) occurs in response to signals, including BMP4. Induction of Blimp1/Prdm1 expression in PGC precursors causes an exit from the pluripotent state, initiates a germ-cell-specific program, represses the somatic program, and initiates an extensive epigenetic program in nascent PGCs. Pluripotent stem cells derived from the ICM (ESC: embryonic stem cells) are more like those derived from PGCs (EGC: embryonic germ cells), and these differ from pluripotent epiblast stem cells (EpiSCs) derived from the epiblast cells.
\end{abstract}

the early down-regulation of Blimp1, which is accompanied by the expression of some of the targets of Blimp1 (Durcova-Hills et al. 2008). During this process, Prmt5 translocates to the cytoplasm where it has a distinct and critical role in pluripotency (see below).

Initiation of Blimp1/Prdm1 expression apparently induces an exit from the very rapidly dividing state seen in pluripotent epiblast cells toward a unipotent germ cell lineage characterized by a significantly increased cell cycle time (Ohinata et al. 2005; K. Hayashi, unpubl.). How this is accomplished precisely is not yet clear, but it is likely that some direct targets of Blimp1, such as c$M y c$, become repressed. Profound epigenetic changes also ensue in nascent PGCs, which culminate in the reexpression of stella as well as of some key pluripotency-specific genes such as Esg1, Sox2, and nanog (Yamaguchi et al. 2005; Yamaji et al. 2008). More importantly, the early epigenetic changes lead to the repression of the Xist gene and reactivation of the inactive $\mathrm{X}$ chromosome (de Napoles et al. 2007; Sugimoto and Abe 2007; Chuva de Sousa Lopes et al. 2008), as well as of the extensive erasure of epigenetic modifications and DNA methylation (Hajkova et al. 2002, 2008).

Blimp1 also causes the initiation of the PGC-specific program in precursor cells, as is evident from the initiation of expression of PGC-specific genes including Dndl, Nanos3, and Prdm 14 (Kurimoto et al. 2008). Notably, Blimp1 also has a critical role in the repression of the somatic program, which continues in the neighboring cells that share common ancestry (Ohinata et al. 2005; Kurimoto et al. 2008). Repression of the somatic program is a key event during specification of germ cells also in other organisms, although the precise mechanisms differ (Blackwell 2004; Strome and Lehmann 2007). Compared to PGC specification in other model organisms such as worms and flies where germ cell fate is initiated through inheritance of germ plasm at the start of development, the epiblast cells in vivo are fast dividing and transcriptionally active. This makes it necessary to convert these cells, which already show initiation of the somatic program, into PGCs. Blimp1 has the potential to form a repressive complex, with Groucho, HDACs, and diverse histone modifiers such as G9a and Prmt5 (Gyory et al. 2004; Ancelin et al. 2006). The precise role of Blimp1 during the very early stages of PGC specification remains to be fully elucidated. Similarly, the precise role of Prmt5, which is detected in all epiblast cells, is also unclear (W.W. Tee, unpubl.). However, the Blimp1-Prmt5 complex is detected in the nucleus of nascent PGCs after E7.5 (Ancelin et al. 2006), where it probably has a role in maintaining early germ cells as they migrate into the developing gonads.

In this context, it will be of interest to determine the relative potential of ES cells and EpiSCs for generating germ cells in vitro. EpiSCs are a stage closer to the cell type from which PGCs emerge during normal development in vivo, assuming that they inherit key properties of postimplantation epiblast cells. Our evidence suggests that EpiSCs can produce PGC precursor cells that show expression of Blimp1, and some of these go onto PGCs and show expression of Stella (K. Hayashi , unpubl.). Note that the culture conditions for ES (LIF and BMP4) differ from the culture conditions for EpiSCs (activin + FGF-2) (Fig. 1) (Brons et al. 2007; Tesar et al. 2007). Importantly, however, these observations demonstrate that PGC specification in mice indeed conforms to the stem cell model. It is noteworthy that human ES cells (hES), which resemble EpiSCs, also show expression of germ-cell-specific markers such as Blimp1 and Prdm14 (Clark and Reijo Pera 2006; Tsuneyoshi et al. 2008).

\section{EPIGENETIC REPROGRAMMING IN EARLY GERM CELLS}

PGCs emerge from the postimplantation pluripotent epiblast cells that have already undergone $\mathrm{X}$ inactivation in female embryos and where some of the pluripotency- 
specific genes, including stella, Sox2, and nanog, are repressed (Surani et al. 2007). However, not only does PGC specification involve activation of the germ-cellspecific genes, but these cells also undergo epigenetic changes that in some respects bring them closer to the pluripotent primitive ectoderm cells in the ICM. The importance of these reprogramming changes in germ cells remains to be fully elucidated, but they could be prerequisite for the eventual establishment of totipotency.

Epigenetic reprogramming in nascent PGCs occurs in a step-wise manner. The initial changes at specification in chromatin modifications in PGCs begin to reinstate the epigenetic status that is closer to the pluripotent stem cells (Ancelin et al. 2006; Seki et al. 2007; Hajkova et al. 2008). The earliest changes include the loss of the repressive mark of dimethylation of lysine 9 on histone H3 (H3K9me2) (Seki et al. 2005; Hajkova et al. 2008). This epigenetic modification is attributed to the histone methyltransferase G9a (also called Ehmt2). Although G9a itself is not down-regulated in early PGCs, its binding partner GLP (or Ehmt1) clearly is (Yabuta et al. 2006), and this affects the activity of the G9a-GLP complex, which may account for the loss of H3K9me 2 modification from PGCs (Seki et al. 2007). However, the involvement of a specific histone demethylase in removing this modification could not be excluded. It is also noteworthy that the inhibition of G9a by a specific inhibitor enhances reprogramming of somatic cells toward the induced pluripotent stem (iPS) cells (Kubicek et al. 2007; Shi et al. 2008). At the same time, there is enhancement of trimethylation of lysine 27 of histone H3 (H3K27me3), concomitant with an increase in the polycomb group enzyme Ezh2 (Hajkova et al. 2008). There is also an enhancement of lysine 4 of histone H3 (H3K4me2 and $\mathrm{H} 3 \mathrm{~K} 4 \mathrm{me} 3$ ) and of histone acetylation marks (such as H3K9ac), which are chromatin modifications associated with gene activation. Notably, these chromatin modifications occur in conjunction with the expression of pluripotency-specific genes Sox2, Oct4, nanog, and stella (Hajkova et al. 2008; Kurimoto et al. 2008). These chromatin modifications also provide permissive conditions for reprogramming and dedifferentiation of early PGCs into pluripotent EG cells (see below). However, in vivo, the unipotent germ cell lineage is probably maintained and propagated by the Blimp1-Prmt5 complex through symmetrical methylation of arginine 3 on histone H2A and $\mathrm{H} 4$ (H2A/H4R3me2s) presumably through repression of target genes (Ancelin et al. 2006).

\section{RESETTING THE GENOME FOR TOTIPOTENCY IN GONADAL PGCs}

One of the hallmarks of epigenetic reprogramming in germ cells is the extensive erasure of the existing epigenetic modifications, including genomic imprints when PGCs enter into the developing gonads (Hajkova et al. 2002, 2008). This includes genome-wide DNA demethylation accompanied by extensive changes in chromatin modifications. The underlying mechanism responsible for DNA demethylation remains to be elucidated, but recent studies have advanced our knowledge of the accompany- ing chromatin changes. The Blimp1-Prmt5 complex, that is evidently detected in the nucleus during migration of PGCs into the gonads, translocates to the cytoplasm (Ancelin et al. 2006), but whether this has any significance for the extensive epigenetic changes in germ cells or merely reflects a major phenotypic change in the lineage is unclear.

The entry of PGCs into the gonads is associated with marked changes in nuclear morphology and a significant increase in nuclear size, which to an extent is reminiscent of changes observed in somatic nuclei during the initiation of reprogramming when transplanted into oocytes (Hajkova et al. 2008). This nuclear enlargement is accompanied by a rapid loss of linker histone $\mathrm{H} 1$ and the loss of chromocenters. There are other extensive changes in histone modifications, some of which are lost transiently, including $\mathrm{H} 3 \mathrm{~K} 27 \mathrm{me} 3$ and $\mathrm{H} 3 \mathrm{~K} 9 \mathrm{me} 3$, whereas others are erased more permanently, including $\mathrm{H} 3 \mathrm{~K} 9 \mathrm{ac}$ and $\mathrm{H} 2 \mathrm{~A} / \mathrm{H} 4 \mathrm{R} 3 \mathrm{me} 2 \mathrm{~s}$. The latter modification is associated with the Blimp1-Prmt5 complex, and the translocation of this complex to the cytoplasm potentially explains the persistent loss of this epigenetic mark, concomitant with the derepression of a target gene $D h x 38$.

The sequence of events associated with the erasure of epigenetic modifications and the large-scale chromatin changes, which most likely involves histone replacement, is of particular interest (Hajkova et al. 2008). Histone variants such as H2A.Z and H3.3, unlike canonical histones H2A, H2B, H3.1, H3.2, and H4, can be incorporated independently of DNA replication at $\mathrm{S}$ phase (Henikoff et al. 2004). Indeed, although H2A.Z was present at significant levels in PGCs early at E10.5, this signal diminished dramatically in PGCs at E11.5-12.5. More significantly however, under appropriate conditions, PGCs from E11.5 could be separated by FACS (fluorescence-activated cell sorting) into two distinct groups, A and $\mathrm{B}$, due to some intrinsic changes in their physical attributes (Fig. 2). Notably, group B is highly transient and detected only during a 3-4-hour duration. These two groups of PGCs exhibit distinct chromatin modifications because PGCs in group A show the presence of the linker histone $\mathrm{H} 1$ as well as high levels of H2A.Z, whereas PGCs in group B are devoid of both. Other modifications associated with histone $\mathrm{H} 3$, such as $\mathrm{H} 3 \mathrm{~K} 27 \mathrm{me} 3$ and $\mathrm{H} 3 \mathrm{~K} 9 \mathrm{ac}$, are also lost in PGCs in group $\mathrm{B}$, including the Blimp1-Prmt5-associated H2A/H4R3me2s. These observations indicate that PGCs in group $\mathrm{B}$ are at a more advanced stage of development compared to those in group A. Furthermore, these chromatin modifications occur in these PGCs in both groups in $\mathrm{G}_{2}$ phase of the cell cycle and therefore must occur independently of DNA replication.

Histone replacement and eviction require deployment of specific histone chaperones, depending on whether the process occurs in conjunction with DNA replication. For example, introduction of canonical histones, such as H3.1, are coupled to DNA replication and require the chaperone CAF-1, but the noncanonical histones, such as H3.3, are associated with HIRA (Tagami et al. 2004). In agreement with the predicted active histone replacement occurring in these PGCs, CAF-1 is not used because it is 

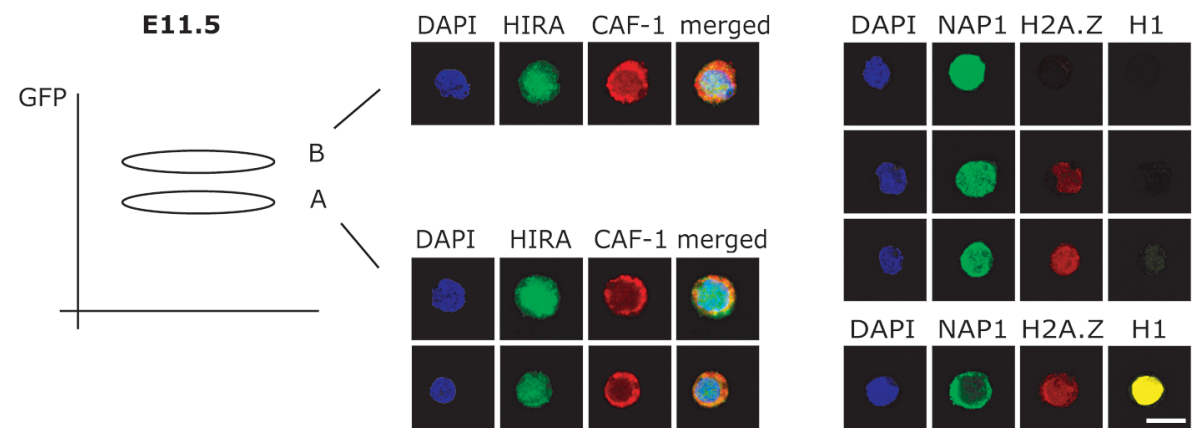

Figure 2. Epigenetic reprogramming in gonadal germ cells at E11.5. In the course of epigenetic reprogramming, PGCs undergo profound changes in nuclear structure and chromatin modifications. Using an Oct4-GFP transgene and based on their physical properties, PGCs can be separated into two distinct subpopulations. PGCs in these populations differ in the presence of linker histone H1, multiple histone modifications, and the histone variant H2A.Z (for details, see the text). This is due to the large-scale histone replacement as documented by the change in the localization of NAP-1 and high levels of nuclear HIRA. The images represent immunofluoresce stainings of fluorescence-activated cell-sorted PGCs at E11.5. Bar, $10 \mu \mathrm{m}$.

detected in the cytoplasm of PGCs, which is rarely seen in most cases (Fig. 2). In contrast, HIRA is detected in the nuclei of PGCs in both groups, consistent with its role in the deposition of noncanonical histones outside the $\mathrm{S}$ phase of the cell cycle. Of great interest is the localization of a histone chaperone, nucleosome assembly protein-1 (NAP-1), which by forming a complex with $\mathrm{H} 2 \mathrm{~A}-\mathrm{H} 2 \mathrm{~B}$ dimers can cause release of $\mathrm{H} 3$ and $\mathrm{H} 4$ during transcription (Lorch et al. 2006). Furthermore NAP-1 has the potential to extract linker histones from chromatin (Kepert et al. 2005). Notably, NAP-1 is detected in the cytoplasm of PGCs in group A, but it translocates to the nucleus in PGCs of group B, concomitant with the loss of H1 and H2A.Z from these cells (Fig. 2). These observations suggest a very significant role for NAP-1 in epigenetic reprogramming in gonadal PGCs.

How the chromatin changes are linked to the erasure of DNA methylation and its underlying mechanism is not yet clear, except that DNA demethylation is already evident in PGCs from group A and therefore precedes the extensive chromatin modifications that follow in PGCs in group B (Hajkova et al. 2008). This being the case, it appears that the chromatin changes and histone replacement observed in PGCs may be a response to DNA demethylation, perhaps because this event compromises the integrity of the DNA.

Deeper insights into the mechanism of epigenetic reprogramming in early PGCs in vivo may provide valuable mechanistic insights on reprogramming of somatic nuclei in the oocyte, which is likely to involve extensive erasure of existing epigenetic modifications involving chromatin modifications and DNA demethylation. Some of this knowledge may also help to unravel the mechanism that underlies the formation of iPS cells from somatic cells.

\section{FROM PGCS TO PLURIPOTENT STEM CELLS}

Although germ cells share some of the core properties of pluripotency with stem cells, this is a unipotent lineage, and early PGCs do not dedifferentiate or participate in the formation of chimeric embryos if transplanted into blastocysts. However, in vitro, E8.5-11.5 PGCs can be induced to undergo dedifferentiation into pluripotent stem cells called embryonic germ (EG) cells when cultured in the presence of leukemia inhibitory factor (LIF), fibroblast growth factor-2 (FGF-2), and stem cell factor (SCF) (Matsui et al. 1992; Resnick et al. 1992). EG cells closely resemble ES cells and not the EpiSCs. This is presumably because specification of PGCs entails epigenetic reprogramming that eventually leads to reactivation of the inactive $\mathrm{X}$ chromosome as well as other important epigenetic modifications (de Napoles et al. 2007; Sugimoto and Abe 2007; Chuva de Sousa Lopes et al. 2008). Reactivation of the inactive paternal X chromosome is also observed in the ICM of blastocyst from which ES cells are derived (Mak et al. 2004; Okamoto et al. 2004). It is possible that these epigenetic modifications reflect other underlying similarities between ICM and PGCs, which may account for the similarities between pluripotent ES and EG cells.

There are, however, also differences between EG and ES cells, the primary difference being that the DNA methylation marks associated with the imprinted genes are predominantly erased during the formation of EG cells (Tada et al. 1997, 1998), an event that is also observed in PGCs in vivo when the germ cells enter into the developing gonads (see above). Other differences between ES and EG cells are evident in cell fusion experiments with somatic cells. Although both ES and EG somatic cell hybrids exhibit reprogramming of the somatic nucleus to pluripotency, there is an additional effect observed with EG cells because these hybrids additionally reveal erasure of the DNA methylation of imprinted genes from somatic nuclei (Tada et al. 1997). Furthermore, hybrids between EG and ES cells result in the erasure of imprints from the ES cells, suggesting that EG cells are dominant over ES cells in this test (Tada et al. 2001). However, the precise nature and mechanism underlying DNA demethylation of imprinted genes are not yet known.

Several mutations, including some in germ-cell-specific genes such as Dnd1, as well as in Pten, Pgct1, and $A k t$ signaling, increase the efficiency of EG derivation from PGCs (Muller et al. 2000; Kimura et al. 2003, 2008; Youngren et al. 2005). This process, to some extent, rep- 
resents a reversal of the events associated with the specification of PGCs from pluripotent cells. EG cells exhibit the ability to undergo differentiation into a variety of cell types. Dedifferentiation of PGCs to pluripotent EG cells requires FGF-2, but only for the first 24-hour period of a process that takes 7-10 days to be completed (DurcovaHills et al. 2006). Addition of FGF-2 after the first 24 hours does not lead to the dedifferentiation process, but the reasons for this are unknown. Recent study of differential gene expression has shown that although there is expression of some of the key pluripotency-specific genes in both PGCs and EG cells, including Oct4, Sox2, and nanog, other genes such as c-Myc, Stat-3, Klf4, Dnmt3l, and Eras are not expressed in E8.5 PGCs (Durcova-Hills et al. 2008), which must be up-regulated during the derivation of EG cells (Fig. 3).

Because Blimp1-Prmt5 is potentially the key complex involved in the maintenance of early germ cell lineage, we anticipated a change in their expression during dedifferentiation of PGCs into pluripotent EG cells. Indeed, among an early event during the derivation of EG cells is the down-regulation of Blimp1 (but not of Prmt5; see below) within 1-2 days of culture (Fig. 3) (Durcova-Hills et al. 2008). Down-regulation of Blimp1 does not occur in the absence of FGF-2 nor if this factor is added 24 hours after the start of the PGC culture, and consequently no EG cells are detected. In contrast, Prmt5 is detected in the nuclei of PGCs in culture for up to 7 days, but it undergoes translocation into the cytoplasm after this time (see below for further discussion). Loss of Blimp1 leads to the up-regulation of some of its direct and indirect targets. Among these targets is Dhx38 (Ancelin et al. 2006), which is detectable as PGCs dedifferentiate into EG cells. However, among the more significant direct targets of

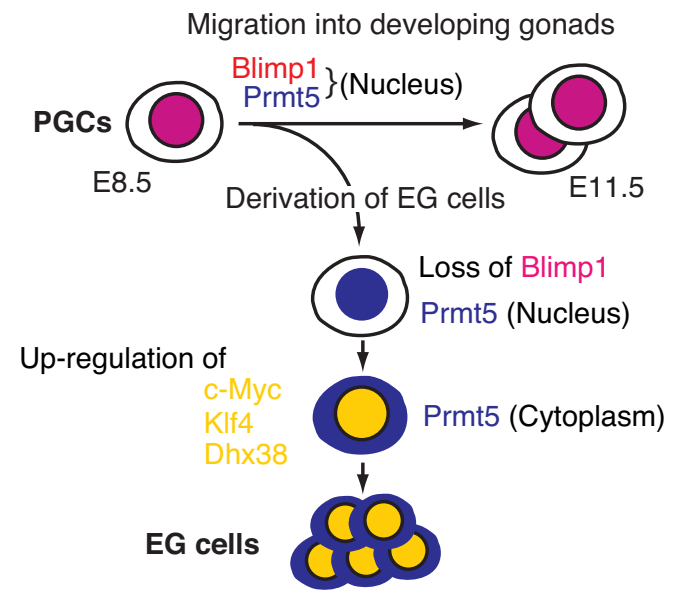

Figure 3. Derivation of pluripotent embryonic germ (EG) cells from primordial germ cells (PGCs). EG cells can be derived from E8.5-11.5 PGCs in vitro when cultured in the presence of FGF-2, LIF, and SCF. Early loss of Blimp1 is followed by translocation of Prmt5 to the cytoplasm and up-regulation of direct targets of Blimp1, including c-Myc, Klf4, and Dhx38. Many epigenetic changes, including erasure of epigenetic modifications and reactivation of the inactive $\mathrm{X}$ chromosome, occur in EG cells as seen in PGCs in vivo.
Blimp1 are c-Myc and Klf4, which begin to be detectable after 7 and 4 days of culture, respectively (Fig. 3) (Durcova-Hills et al. 2008). It is also very likely that Eras may also be up-regulated during dedifferentiation of PGCs. It is possible that during PGC specification from epiblast cells, these are among the initial and key genes to be repressed in response to the expression of Blimp1. They are also among the key genes that along with Sox2 and Oct 4 have a critical role in reprogramming of somatic cells into pluripotent cells.

These studies also reveal the importance of the LIF/STAT3 signaling pathway during reprogramming of PGCs to EG cells. STAT3 is undetectable in E8.5 PGCs, but it is clearly present in EG cells, and it starts to be detected predominantly in the cytoplasm when PGCs undergo dedifferentiation at about day 4 of culture; however, it is also occasionally seen in the nuclei of these cells and in older cultures when EG cells become established. LIF is known to enhance the survival and proliferation of PGCs. Unlike FGF-2, LIF is apparently not required during the first 24 hours of culture, but the addition of LIF after a 48-hour culture of PGCs improves the derivation of EG cells. Furthermore, the addition of WHI-P131 (1-5 $\mu \mathrm{M})$, an inhibitor of the Jak/STAT3 signaling pathway to the culture medium, also abrogated the derivation of EG cells (Durcova-Hills et al. 2008).

Further investigations have shown that Trichostatin A (TSA; $5 \mathrm{ng} / \mathrm{ml}$ ), an inhibitor of histone deacetylases (HDACs), can substitute for FGF-2 (Durcova-Hills et al. 2008). TSA proved to be very effective for the derivation of EG cells, and the process of dedifferentiation was also accelerated by TSA when the EG colonies were detected 1-2 days earlier. There was also a quicker down-regulation of Blimp1 from PGCs, which was already evident within 1 day after culture. The mechanism through which TSA action manifests itself and accelerates the down-regulation of Blimp1 from PGCs in culture is unknown, but this could involve epigenetic modifications of certain loci during this process. Because there is the presence of feeder cells in culture, it is also possible that TSA may sensitize PGCs to some of the cytokines that are produced by these cells to induce reprogramming of PGCs.

It is of interest to compare reprogramming of PGCs with that of neural progenitor cell lines. The latter are selfrenewing cells when cultured under appropriate conditions but they are not pluripotent. In contrast, PGCs show expression of key pluripotency-specific genes, but early PGCs in vivo, unlike EG cells and neural progenitors, are not self-renewing. However, both cell types can be converted into pluripotent stem cells.

\section{MULTIPLE ROLES OF PRMT5: THE LINK BETWEEN PLURIPOTENT STEM CELLS AND GERM CELLS}

A potentially important observation that emerges from studies on reprogramming of PGCs to EG cells is the apparent multiple roles of Prmt5, an enzyme with specificity for symmetrical dimethylation of arginine 3 of histones $\mathrm{H} 2 \mathrm{~A}$ and H4. Additionally, Prmt5 has been shown to methylate both histones and nonhistone substrates (Bedford and 
Richard 2005). In conjunction with its complex with Blimp1 detected in the nuclei of early PGCs (Ancelin et al. 2006), Prmt5 is responsible for the symmetrical dimethylation of arginine 3 of histone $\mathrm{H} 2 \mathrm{~A} / \mathrm{H} 4$ (H2A/H4R3me2s). This repressive modification is presumably responsible for silencing target genes and maintaining the early germ cell lineage. However, whereas Blimp1 is rapidly down-regulated during the derivation of pluripotent EG cells from PGCs, Prmt5 translocates to the cytoplasm (Fig. 3), where it is detected in the absence of Blimp1 in pluripotent stem cells (W.W. Tee, unpubl.). Indeed, Prmt5 is predominantly detected in the cytoplasm of all pluripotent stem cells, including ES cells, as well as in the pluripotent epiblast cells in vivo. Our ongoing studies indicate that Prmt5 may be crucial for pluripotency and for germ cell specification. This is in addition to the role of the Blimp1-Prmt5 complex in the maintenance of the germ cell lineage during the migration of PGCs into the gonads. The apparent involvement of Prmt5 in pluripotency and in the germ cell lineage provides a major opportunity to explore the links between pluripotent cells and the germ cell lineage.

Preliminary studies indicate that Prmt5 is maternally inherited protein in the oocyte, and its loss of function results in very early embryonic lethality. Loss of Prmt5 abrogates pluripotency and induces differentiation of ES cells. Prmt5 is detected predominantly in the cytoplasm of ES cells, and we have identified several novel interactors of Prmt5 in ES cells, where presumably some of the components serve as the substrates of this enzyme. Notably, some of these interactors have previously been demonstrated to be important for ES pluripotency (W.W. Tee, unpubl.). We are currently investigating how Prmt5 potentially integrates into the pluripotency circuitry.

Prmt5 is also present in the cytoplasm of pluripotent epiblast cells, and here it may have an additional role during the formation of PGC precursors and in events leading to the specification of germ cells. This possibility is further suggested by the observation that in Drosophila, a Prmt5 homolog (Capsuleen/Dart5) forms together with MEP50, a methylosome that is important for the localization of Tudor to the pole plasm (Anne and Mechler 2005). Loss of function of any of these components in flies results in the loss of germ cells. Recent evidence suggests the presence of a Tudor domain protein, Tdrd5, and MEP50 in the cytoplasm of ES cells, which interact with Prmt5 (W.W. Tee, unpubl.). Notably, Tdrd5 levels increase when Blimp1 expression commences in PGC precursors. This raises the possibility that Prmt5-Tdrd5 interaction in the cytoplasm of PGC precursors may have a role during PGC specification in mice. Following PGC specification, Tdrd5 is downregulated and Prmt5 translocates to the nucleus, where as part of a complex with Blimp1, it performs the role of maintaining the early germ cell lineage as described above. Detailed analysis of the multiple roles of Prmt5 in pluripotency and germ cells should further reveal how the two phenotypic states are linked and regulated.

\section{PERSPECTIVE}

Evidence shows that the germ cell lineage and pluripotent stem cells are intimately linked entities, and they share many core properties despite germ cells being unipotent. This link can be attributed to the stem cell mode of germ cell specification in mice. Recent derivation of pluripotent iPS cells directly from adult somatic cells, which have the potential to generate germ cells, suggests that once pluripotency is restored to somatic cells, they also acquire the potential for specification into germ cells. This can occur even when such cells are introduced directly into blastocysts, thus bypassing preimplantation development. Further studies may lead to the derivation of germ cells from fully or partially reprogrammed somatic cells directly in vitro without reintroduction into blastocysts.

The molecular basis for the similarities and differences between PGCs and pluripotent stem cells is also becoming more evident. It is possible that detailed investigations on the role of Prmt5 will enhance our understanding of the properties of pluripotent stem cells and unipotent germ cells, and indeed on reprogramming of somatic cells to a pluripotent state.

\section{ACKNOWLEDGMENTS}

We thank all members of the lab for their valuable contributions. The work described in the paper was funded by the Medical Research Council (G.D.-H.) and the Wellcome Trust (M.A.S.).

\section{REFERENCES}

Ancelin, K., Lange, U.C., Hajkova, P., Schneider, R., Bannister, A.J., Kouzarides, T., and Surani, M.A. 2006. Blimp1 associates with Prmt5 and directs histone arginine methylation in mouse germ cells. Nat. Cell Biol. 8: 623-630.

Anne, J. and Mechler, B.M. 2005. Valois, a component of the nuage and pole plasm, is involved in assembly of these structures, and binds to Tudor and the methyltransferase Capsuléen. Development 132: 2167-2177.

Bedford, M.T. and Richard, S. 2005. Arginine methylation an emerging regulator of protein function. Mol. Cell 18: 263-272.

Blackwell, T.K. 2004. Germ cells: Finding programs of mass repression. Curr. Biol. 14: R229-R230.

Brons, I.G., Smithers, L.E., Trotter, M.W., Rugg-Gunn, P., Sun, B., Chuva de Sousa Lopes, S.M., Howlett, S.K., Clarkson, A., Ahrlund-Richter, L., Pedersen, R.A., and Vallier, L. 2007. Derivation of pluripotent epiblast stem cells from mammalian embryos. Nature 448: 191-195.

Chuva de Sousa Lopes, S.M., Hayashi, K., Shovlin, T.C., Mifsud, W., Surani, M.A., and McLaren, A. 2008. X chromosome activity in mouse XX primordial germ cells. PLoS Genet. 4: e30.

Clark, A.T. and Reijo Pera, R.A. 2006. Modeling human germ cell development with embryonic stem cells. Regen. Med. 1: 85-93.

de Napoles, M., Nesterova, T., and Brockdorff, N. 2007. Early loss of Xist RNA expression and inactive X chromosome associated chromatin modification in developing primordial germ cells. PLOS ONE 2: e860.

Durcova-Hills, G., Adams, I.R., Barton, S.C., Surani, M.A., and McLaren, A. 2006. The role of exogenous fibroblast growth factor-2 on the reprogramming of primordial germ cells into pluripotent stem cells. Stem Cells 24: 1441-1449.

Durcova-Hills, G., Tang, F., Doody, G., Tooze, R., and Surani, M.A. 2008. Reprogramming primordial germ cells into pluripotent stem cells. PLOS ONE (in press).

Gyory, I., Wu, J., Fejér, G., Seto, E., and Wright, K.L. 2004. PRDI-BF1 recruits the histone $\mathrm{H} 3$ methyltransferase G9a in transcriptional silencing. Nat. Immunol. 5: 299-308.

Hajkova, P., Erhardt, S., Lane, N., Haaf, T., El-Maarri, O., Reik, W., Walter, J., and Surani, M.A. 2002. Epigenetic reprogramming in mouse primordial germ cells. Mech. Dev. 117: 15-23. 
Hajkova, P., Ancelin, K., Waldmann, T., Lacoste, N., Lange, U.C., Cesari, F., Lee, C., Almouzni, G., Schneider, R., and Surani, M.A. 2008. Chromatin dynamics during epigenetic reprogramming in the mouse germ line. Nature 452: 877-881.

Hayashi, K., Kobayashi, T., Umino, T., Goitsuka, R., Matsui, Y., and Kitamura, D. 2002. SMAD1 signaling is critical for initial commitment of germ cell lineage from mouse epiblast. Mech. Dev. 118: 99-109.

Hayashi, K., de Sousa Lopes, S.M., and Surani, M.A. 2007. Germ cell specification in mice. Science 316: 394-396.

Henikoff, S., Furuyama, T., and Ahmad, K. 2004. Histone variants, nucleosome assembly and epigenetic inheritance. Trends Genet. 20: 320-326.

Kepert, J.F., Mazurkiewicz, J., Heuvelman, G.L., Toth, K.F., and Rippe, K. 2005. NAP1 modulates binding of linker histone $\mathrm{H} 1$ to chromatin and induces an extended chromatin fiber conformation. J. Biol. Chem. 280: 34063-34072.

Kimura, T., Suzuki, A., Fujita, Y., Yomogida, K., Lomeli, H., Asada, N., Ikeuchi, M., Nagy, A., Mak, T.W., and Nakano, T. 2003. Conditional loss of PTEN leads to testicular teratoma and enhances embryonic germ cell production. Development 130: $1691-1700$.

Kimura, T., Tomooka, M., Yamano, N., Murayama, K., Matoba, S., Umehara, H., Kanai, Y., and Nakano, T. 2008. AKT signaling promotes derivation of embryonic germ cells from primordial germ cells. Development 135: 869-879.

Kubicek, S., O’Sullivan, R.J., August, E.M., Hickey, E.R., Zhang, Q., Teodoro, M.L., Rea, S., Mechtler, K., Kowalski, J.A., Homon, C.A., Kelly, T.A., and Jenuwein, T. 2007. Reversal of $\mathrm{H} 3 \mathrm{~K} 9 \mathrm{me} 2$ by a small-molecule inhibitor for the G9a histone methyltransferase. Mol. Cell 25: 473-481.

Kurimoto, K., Yabuta, Y., Ohinata, Y., Shigeta, M., Yamanaka, K., and Saitou, M. 2008. Complex genome-wide transcription dynamics orchestrated by Blimp1 for the specification of the germ cell lineage in mice. Genes Dev. 22: 1617-1635.

Lawson, K.A. and Hage, W.J. 1994. Clonal analysis of the origin of primordial germ cells in the mouse. Ciba Found. Symp. 182: 68-91.

Lawson, K.A., Dunn, N.R., Roelen, B.A., Zeinstra, L.M., Davis, A.M., Wright, C.V., Korving, J.P., and Hogan, B.L. 1999. $\mathrm{Bmp} 4$ is required for the generation of primordial germ cells in the mouse embryo. Genes Dev. 13: 424-436.

Lorch, Y., Maier-Davis, B., and Kornberg, R.D. 2006. Chromatin remodeling by nucleosome disassembly in vitro. Proc. Natl. Acad. Sci. 103: 3090-3093.

Mak, W., Nesterova, T.B., de Napoles, M., Appanah, R., Yamanaka, S., Otte, A.P., and Brockdorff, N. 2004. Reactivation of the paternal X chromosome in early mouse embryos. Science 303: 666-669.

Matsui, Y., Zsebo, K., and Hogan, B.L. 1992. Derivation of pluripotential embryonic stem cells from murine primordial germ cells in culture. Cell 70: 841-847.

McLaren, A. 2003. Primordial germ cells in the mouse. Dev. Biol. 262: 1-15.

McMahon, A., Fosten, M., and Monk, M. 1981. Random Xchromosome inactivation in female primordial germ cells in the mouse. J. Embryol. Exp. Morphol. 64: 251-258.

Muller, A.J., Teresky, A.K., and Levine, A.J. 2000. A male germ cell tumor-susceptibility-determining locus, pgct 1 , identified on murine chromosome 13. Proc. Natl. Acad. Sci. 97: $8421-8426$

Ohinata, Y., Payer, B., O'Carroll, D., Ancelin, K., Ono, Y., Sano, M., Barton, S.C., Obukhanych, T., Nussenzweig, M. Tarakhovsky, A., Saitou, M., and Surani, M.A. 2005. Blimp1 is a critical determinant of the germ cell lineage in mice. Nature 436: 207-213.

Okamoto, I., Otte, A.P., Allis, C.D., Reinberg, D., and Heard, E. 2004. Epigenetic dynamics of imprinted $X$ inactivation during early mouse development. Science 303: 644-649.

Resnick, J.L., Bixler, L.S., Cheng, L., and Donovan, P.J. 1992. Long-term proliferation of mouse primordial germ cells in culture. Nature 359: 550-551.

Seki, Y., Hayashi, K., Itoh, K., Mizugaki, M., Saitou, M., and Matsui, Y. 2005. Extensive and orderly reprogramming of genome-wide chromatin modifications associated with specification and early development of germ cells in mice. Dev. Biol. 278: $440-458$

Seki, Y., Yamaji, M., Yabuta, Y., Sano, M., Shigeta, M., Matsui, Y., Saga, Y., Tachibana, M., Shinkai, Y., and Saitou, M. 2007. Cellular dynamics associated with the genome-wide epigenetic reprogramming in migrating primordial germ cells in mice. Development 134: 2627-2638.

Shi, Y., Do, J.T., Desponts, C., Hahm, H.S., Scholer, H.R., and Ding, S. 2008. A combined chemical and genetic approach for the generation of induced pluripotent stem cells. Cell Stem Cell 2: 525-528.

Strome, S. and Lehmann, R. 2007. Germ versus soma decisions: Lessons from flies and worms. Science 316: 392-393.

Sugimoto, M. and Abe, K. 2007. X chromosome reactivation initiates in nascent primordial germ cells in mice. PLoS Genet. 3: e116.

Surani, M.A., Ancelin, K., Hajkova, P., Lange, U.C., Payer, B., Western, P., and Saitou, M. 2004. Mechanism of mouse germ cell specification: A genetic program regulating epigenetic reprogramming. Cold Spring Harbor Symp. Quant. Biol. 69: $1-9$

Surani, M.A., Hayashi, K., and Hajkova, P. 2007. Genetic and epigenetic regulators of pluripotency. Cell 128: 747-762.

Tada, M., Tada, T., Lefebvre, L., Barton, S.C., and Surani, M.A. 1997. Embryonic germ cells induce epigenetic reprogramming of somatic nucleus in hybrid cells. $E M B O J$. 16: 6510-6520.

Tada, T., Tada, M., Hilton, K., Barton, S.C., Sado, T., Takagi, N., and Surani, M.A. 1998. Epigenotype switching of imprintable loci in embryonic germ cells. Dev. Genes Evol. 207: 551-561.

Tada, M., Takahama, Y., Abe, K., Nakatsuji, N., and Tada, T. 2001. Nuclear reprogramming of somatic cells by in vitro hybridization with ES cells. Curr. Biol. 11: 1553-1558.

Tagami, H., Ray-Gallet, D., Almouzni, G., and Nakatani, Y. 2004. Histone H3.1 and H3.3 complexes mediate nucleosome assembly pathways dependent or independent of DNA synthesis. Cell 116: 51-61.

Tesar, P.J., Chenoweth, J.G., Brook, F.A., Davies, T.J., Evans, E.P., Mack, D.L., Gardner, R.L., and McKay, R.D. 2007. New cell lines from mouse epiblast share defining features with human embryonic stem cells. Nature 448: 196-199.

Tremblay, K.D., Dunn, N.R., and Robertson, E.J. 2001. Mouse embryos lacking Smad1 signals display defects in extraembryonic tissues and germ cell formation. Development 128: $3609-3621$.

Tsuneyoshi, N., Sumi, T., Onda, H., Nojima, H., Nakatsuji, N., and Suemori, H. 2008. PRDM14 suppresses expression of differentiation marker genes in human embryonic stem cells. Biochem. Biophys. Res. Commun. 367: 899-905.

Vincent, S.D., Dunn, N.R., Sciammas, R., Shapiro-Shalef, M., Davis, M.M., Calame, K., Bikoff, E.K., and Robertson, E.J. 2005. The zinc finger transcriptional repressor Blimp1/Prdm1 is dispensable for early axis formation but is required for specification of primordial germ cells in the mouse. Development 132: $1315-1325$

Yabuta, Y., Kurimoto, K., Ohinata, Y., Seki, Y., and Saitou, M. 2006. Gene expression dynamics during germline specification in mice identified by quantitative single-cell gene expression profiling. Biol. Reprod. 75: 705-716.

Yamaguchi, S., Kimura, H., Tada, M., Nakatsuji, N., and Tada, T. 2005. Nanog expression in mouse germ cell development. Gene Expr. Patterns 5: 639-646.

Yamaji, M., Seki, Y., Kurimoto, K., Yabuta, Y., Yuasa, M., Shigeta, M., Yamanaka, K., Ohinata, Y., and Saitou, M. 2008. Critical function of Prdm14 for the establishment of the germ cell lineage in mice. Nat. Genet. 40: 1016-1022.

Youngren, K.K., Coveney, D., Peng, X., Bhattacharya, C., Schmidt, L.S., Nickerson, M.L., Lamb, B.T., Deng, J.M., Behringer, R.R., Capel, B., Rubin, E.M., Nadeau, J.H., and Matin, A. 2005. The Ter mutation in the dead end gene causes germ cell loss and testicular germ cell tumours. Nature 435: 360-364. 


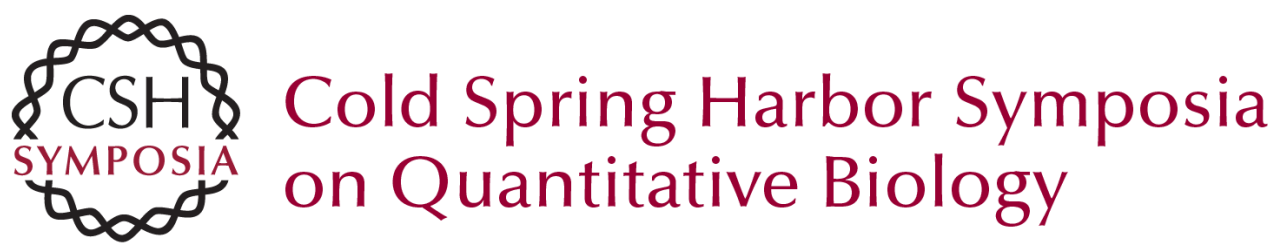

\section{Germ Line, Stem Cells, and Epigenetic Reprogramming}

M.A. Surani, G. Durcova-Hills, P. Hajkova, et al.

Cold Spring Harb Symp Quant Biol 2008 73: 9-15 originally published online November 6, 2008 Access the most recent version at doi:10.1101/sqb.2008.73.015

References This article cites 50 articles, 17 of which can be accessed free at: http://symposium.cshlp.org/content/73/9.full.html\#ref-list-1

License

Email Alerting Receive free email alerts when new articles cite this article - sign up in the Service box at the top right corner of the article or click here. 